\title{
Synthesis and Evaluation of a Water-Soluble Hyperbranched Polymer as Enhanced Oil Recovery Chemical
}

\author{
Nanjun Lai, ${ }^{1,2}$ Xiaoping Qin, ${ }^{1,3}$ Zhongbin Ye, ${ }^{1,2}$ Qin Peng, ${ }^{2}$ Yan Zhang, ${ }^{2}$ and Zheng Ming ${ }^{2}$ \\ ${ }^{1}$ State Key Laboratory of Oil and Gas Reservoir Geology and Exploitation, Southwest Petroleum University, Chengdu 610500, China \\ ${ }^{2}$ College of Chemistry and Chemical Engineering, Southwest Petroleum University, Chengdu 610500, China \\ ${ }^{3}$ College of Petroleum Engineering, Southwest Petroleum University, Chengdu 610500, China
}

Correspondence should be addressed to Xiaoping Qin; 948801727@qq.com

Received 15 August 2013; Revised 1 October 2013; Accepted 3 October 2013

Academic Editor: Marinos Pitsikalis

Copyright (C) 2013 Nanjun Lai et al. This is an open access article distributed under the Creative Commons Attribution License, which permits unrestricted use, distribution, and reproduction in any medium, provided the original work is properly cited.

\begin{abstract}
A novel hyperbranched polymer was synthesized using acrylamide (AM), acrylic acid (AA), $N$-vinyl-2-pyrrolidone (NVP), and dendrite functional monomer as raw materials by redox initiation system in an aqueous medium. The hyperbranched polymer was characterized by infrared (IR) spectroscopy, ${ }^{1} \mathrm{H}$ NMR spectroscopy, ${ }^{13} \mathrm{C}$ NMR spectroscopy, elemental analysis, and scanning electron microscope (SEM). The viscosity retention rate of the hyperbranched polymer was $22.89 \%$ higher than that of the AM/AA copolymer (HPAM) at $95^{\circ} \mathrm{C}$, and the viscosity retention rate was $8.17 \%, 12.49 \%$, and $13.68 \%$ higher than that of HPAM in $18000 \mathrm{mg} / \mathrm{L}$ $\mathrm{NaCl}, 1800 \mathrm{mg} / \mathrm{L} \mathrm{CaCl}_{2}$, and $1800 \mathrm{mg} / \mathrm{L} \mathrm{MgCl}_{2} \cdot 6 \mathrm{H}_{2} \mathrm{O}$ brine, respectively. The hyperbranched polymer exhibited higher apparent viscosity (25.2 mPa.s versus $8.1 \mathrm{mPa} \cdot \mathrm{s})$ under $500 \mathrm{~s}^{-1}$ shear rate at $80^{\circ} \mathrm{C}$. Furthermore, the enhanced oil recovery (EOR) of $1500 \mathrm{mg} / \mathrm{L}$ hyperbranched polymer solutions was up to $23.51 \%$ by the core flooding test at $80^{\circ} \mathrm{C}$.
\end{abstract}

\section{Introduction}

Polymer flooding plays an important role in enhanced oil recovery (EOR) [1-7]. However, the most widely used watersoluble polymers, polyacrylamide and partially hydrolyzed polyacrylamide, are not suitable for high temperature, high salinity, and high flow rate injection owing to hydrolysis, decomposition, degradation, shear damage, and so forth $[1,6$, $8-11]$. With the growing demand for petroleum resources, the water-soluble polymer, which displays perfect temperatureresistance, salt-resistance, and shear-resistance in harsh conditions, is a challenge to the oil filed chemists [12].

In recent decades, many studies demonstrated that acrylamide (AM) copolymerized with an applicable functional monomer, such as $\mathrm{N}, \mathrm{N}$-dimethylacrylamide, methacrylamide, $\mathrm{N}$-vinyl-2-pyrrolidone (NVP), 2-acrylamido2-methyl-1-propanesulfonic acid (AMPS), sodium allylsulfonate, acrylic acid (AA), and ethylenesulfonic acid, could obtain more satisfying polymer possessing better temperature-resistance and salt-resistance for EOR [1217]. What is more, dendrite polymers, star polymers, and hyperbranched polymers, which may exhibit excellent shear-resistance performance due to their special network structure, have been reported widely in many other applied fields [18-25]. This special network structure may reduce the effect of shear on polymer molecular chain, which may recover to a certain extent after being cut and eventually obtaining higher viscosity retention rate.

Keeping in mind all the above points, herein, a novel hyperbranched polymer was synthesized by free radical polymerization based on AM, AA, NVP, and dendrite functional monomer aiming to obtain satisfying temperature-resistance, salt-resistance, and shear-resistance.

\section{Experimental}

2.1. Chemicals and Reagents. Ethylenediamine (EDA, AR), methyl acrylate (AR), methanol (AR), ethanol (AR), $N$, $\mathrm{N}$-dimethylformamide (DMF, AR), maleic anhydride (AR), acrylic acid (AR), acrylamide (AR), $N$-vinyl-2-pyrrolidone (NVP, AR), sodium hydroxide (AR), sodium hydrogen sulfite $\left(\mathrm{NaHSO}_{3}, \mathrm{AR}\right)$, ammonium persulfate $\left(\left(\mathrm{NH}_{4}\right)_{2} \mathrm{~S}_{2} \mathrm{O}_{8}, \mathrm{AR}\right)$, sodium chloride $(\mathrm{NaCl}, \mathrm{AR})$, calcium 


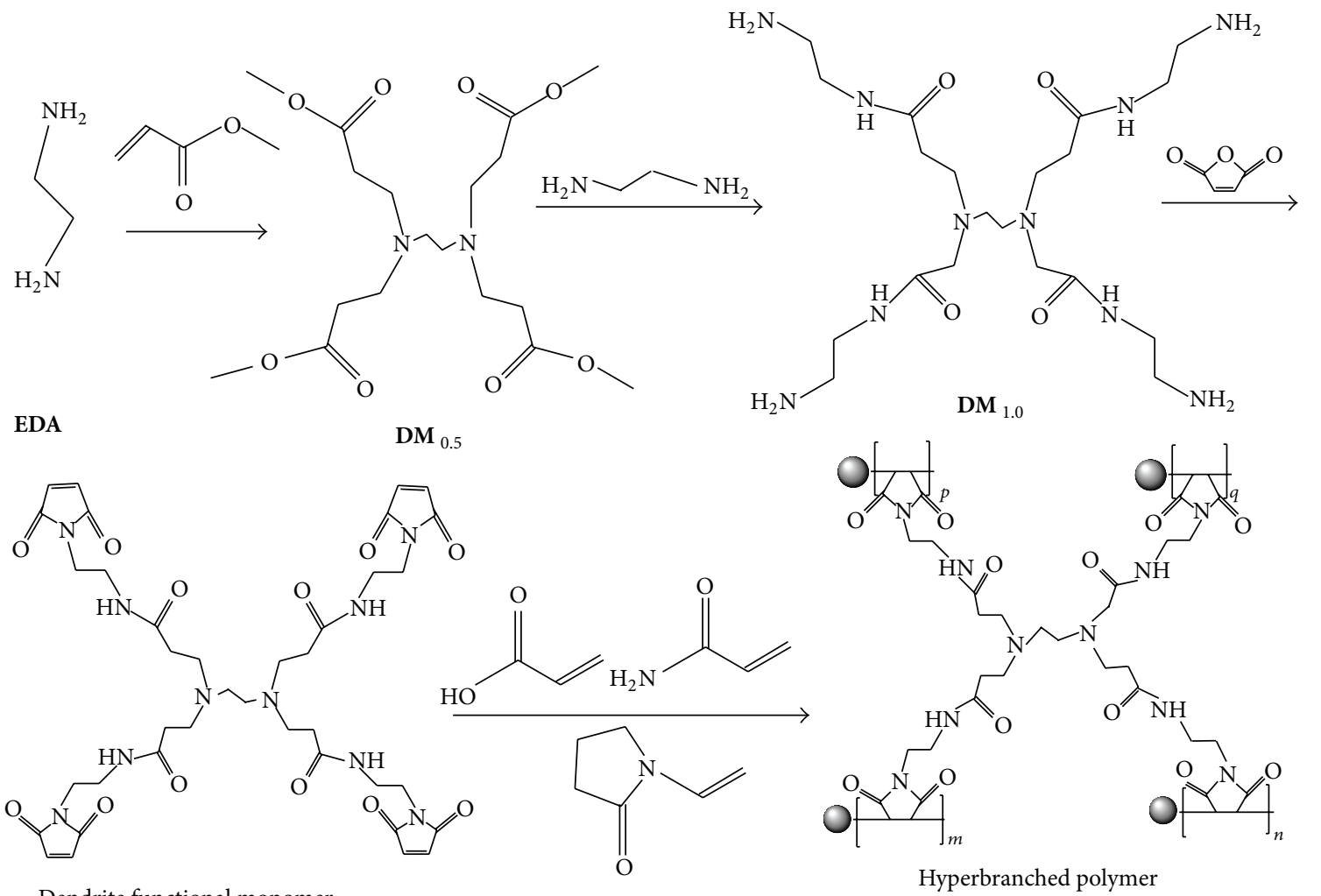

Dendrite functional monomer

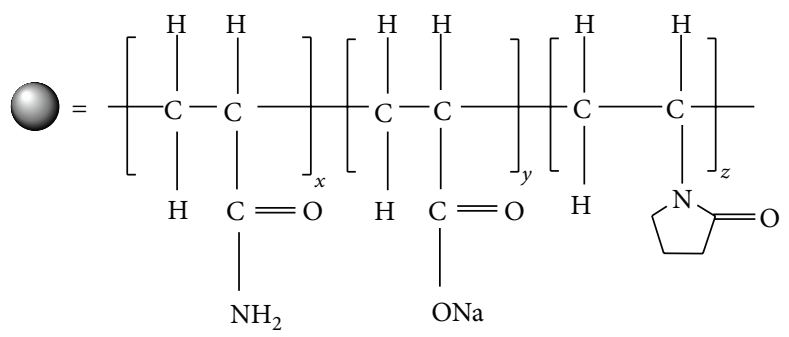

Scheme 1: The synthesis route of the hyperbranched polymer.

chloride anhydrous $\left(\mathrm{CaCl}_{2}, \mathrm{AR}\right)$, magnesium chloride hexahydrate $\left(\mathrm{MgCl}_{2} \cdot 6 \mathrm{H}_{2} \mathrm{O}, \mathrm{AR}\right)$, potassium chloride $(\mathrm{KCl}$, $\mathrm{AR})$, sodium sulfate $\left(\mathrm{Na}_{2} \mathrm{SO}_{4}, \mathrm{AR}\right)$, and sodium bicarbonate $\left(\mathrm{NaHCO}_{3}, \mathrm{AR}\right)$ were purchased from Chengdu Kelong Chemical Reagent Factory (Sichuan, China). All chemicals and reagents were used as received without any further purification.

2.2. Synthesis of Dendrite Functional Monomer. Synthesis of 0.5 generation dendritic macromolecule $\left(\mathrm{DM}_{0.5}\right): 113.5 \mathrm{~g}$ methyl acrylate was added into a three-necked flask with methanol as solvent, and then $9.0 \mathrm{~g}$ ethylenediamine was dripped into the stirred solution in the three-necked flask. The reaction time was $24 \mathrm{~h}$ at $25^{\circ} \mathrm{C}$. After reaction, the product was purified by vacuum distillation and silica gel column. Then the $\mathrm{DM}_{0.5}$ was obtained $[18,20]$.

Synthesis of 1.0 generation dendritic macromolecule $\left(\mathrm{DM}_{1.0}\right): 40.0 \mathrm{~g}$ ethylenediamine was added into a threenecked flask with methanol as solvent, then $20.2 \mathrm{~g} \mathrm{DM}_{0.5}$ was dripped into the stirred solution in the three-necked flask.
The reaction time was $48 \mathrm{~h}$ at $25^{\circ} \mathrm{C}$, and the product was the $\mathrm{DM}_{1.0}$, which was purified by vacuum distillation and silica gel column $[18,20]$.

Modification of $\mathrm{DM}_{1.0}: 4.4 \mathrm{~g}$ maleic anhydride was added into a round-bottom flask with $\mathrm{N}, \mathrm{N}$-dimethylformamide as solvent, and $8.0 \mathrm{~g} \mathrm{DM}_{1.0}$ was dripped into the round-bottom flask. The reaction time was $8 \mathrm{~h}$ at $70^{\circ} \mathrm{C}$, and the dendrite functional monomer was obtained by vacuum filtration.

2.3. Synthesis of Hyperbranched Polymer and HPAM. Firstly, $7.00 \mathrm{~g} \mathrm{AM}, 2.95 \mathrm{~g}$ AA, $0.01 \mathrm{~g}$ dendrite functional monomer, $0.04 \mathrm{~g} \mathrm{NVP}$, and $1.65 \mathrm{~g}$ sodium hydroxide were added into a $100 \mathrm{~mL}$ three-necked flask with $38.35 \mathrm{~mL}$ distilled water as solvent. Secondly, $0.04 \mathrm{~g} \mathrm{NaHSO}-\left(\mathrm{NH}_{4}\right)_{2} \mathrm{~S}_{2} \mathrm{O}_{8}$ initiator ( mol ratio $=1: 1)$ was taken along with distilled water in the three-necked flask. And then, the copolymerization was carried out for $4 \mathrm{~h}$ at $50^{\circ} \mathrm{C}$ under nitrogen atmosphere. Finally, the hyperbranched polymer was obtained by ethanol washing, drying, and pulverizing. The synthesis route of the hyperbranched polymer is shown in Scheme 1. 
TABLE 1: TDS and chemical composition of the brine.

\begin{tabular}{lcccccccc}
\hline Composition & $\mathrm{NaCl}$ & $\mathrm{KCl}$ & $\mathrm{CaCl}_{2}$ & $\mathrm{MgCl}_{2} \cdot 6 \mathrm{H}_{2} \mathrm{O}$ & $\mathrm{Na}_{2} \mathrm{SO}_{4}$ & $\mathrm{NaHCO}_{3}$ & $\mathrm{TDS}$ \\
\hline Content $(\mathrm{g} / \mathrm{L})$ & 8.007 & 0.155 & 0.762 & 2.183 & 0.138 & 0.516 & 10.599 \\
\hline
\end{tabular}

The AM/AA copolymer (HPAM) was synthesized using $7.00 \mathrm{~g} \mathrm{AM}$ and $2.95 \mathrm{~g}$ AA as raw materials through the same synthesis method.

2.4. Characterization. Infrared (IR) spectra of the dendrite functional monomer and hyperbranched polymer were measured with $\mathrm{KBr}$ pellets using Perkin Elmer RX-1 spectrophotometer (Beijing Rayleigh Analytical Instrument, China). ${ }^{1} \mathrm{H}$ NMR spectroscopy and ${ }^{13} \mathrm{C}$ NMR spectroscopy of the dendrite functional monomer, hyperbranched polymer, and HPAM were recorded on Bruker AC-E 200 spectrometer (Bruker BioSpin, Switzerland) at $400 \mathrm{MHz}$ with $\mathrm{D}_{2} \mathrm{O}$ as solvent. The elemental analysis of the hyperbranched polymer and HPAM was carried out through Vario EL III elemental analyzer (Wuxi Chuangxiang Analytical Instrument, China). The microstructures of the hyperbranched polymer and HPAM were observed via Quanta 450 scanning electron microscope (SEM, FEI Company, USA).

2.5. Weight-Average Molecular Weight. The weight-average molecular weight $\left(M_{w}\right)$ of the hyperbranched polymer and HPAM was determined by a BI-200SM wide angle dynamic/static laser light scattering apparatus at $25^{\circ} \mathrm{C}$. The laser wavelength was $532 \mathrm{~nm}$. The $M_{w}$ of the hyperbranched polymer and HPAM can be obtained by the following equation $[26,27]$ :

$$
\frac{K C}{R_{v v}(q)} \cong \frac{1}{M_{w}}\left(1+\frac{1}{3}\left\langle R_{g}\right\rangle^{2} q^{2}\right),
$$

where $C$ is the concentration of polymer solution, $\mathrm{g} / \mathrm{mL} ; K$ is a constant; $\left\langle R_{g}\right\rangle$ is the average radius of gyration, $\mathrm{nm} ; R_{v v}(q)$ is the Rayleigh ratio; and $q=\left(4 \pi n / \lambda_{o}\right) \sin (\theta / 2)$ with $n, \lambda_{o}$, and $\theta$ being the solvent refractive index, the wavelength of laser in vacuo, and the scattering angle, respectively.

2.6. Temperature-Resistance and Salt-Resistance. Hyperbranched polymer and HPAM solutions $(5000 \mathrm{mg} / \mathrm{L})$ were prepared with distilled water. The apparent viscosity of these polymers solutions was tested using Brookfiled DV-III viscometer at different temperatures. The salt-resistance performance was studied by increasing salt $\left(\mathrm{NaCl}, \mathrm{CaCl}_{2}\right.$, or $\mathrm{MgCl}_{2} \cdot 6 \mathrm{H}_{2} \mathrm{O}$ ) concentration, and then the apparent viscosity of these polymers solutions was measured via Brookfield DV-III viscometer at $20^{\circ} \mathrm{C}$.

2.7. Shear-Resistance. Shear-resistance of the hyperbranched polymer and HPAM solutions $(5000 \mathrm{mg} / \mathrm{L})$ was measured using HAAKE RS 6000 rotational rheometer (Thermo Fisher Scientific, Germany) at $80^{\circ} \mathrm{C}[12,15-17]$. The samples were prepared with distilled water.
2.8. Core Flooding Experiments. Two Berea sandstone cores were used to study the EOR ability of these copolymer solutions $(1500 \mathrm{mg} / \mathrm{L})$ prepared with brine. Total dissolved solids (TDS) and chemical composition of the brine are listed in Table 1. The core was placed into Hassler core holder with 1.0 MPa backpressure and 3.0 MPa confining pressure. It was saturated with the brine, and then it was saturated with crude oil $\left(62.2 \mathrm{mPa} \cdot \mathrm{s}\right.$ at $\left.80^{\circ} \mathrm{C}\right)$ at different injection rate $(0.1-0.2 \mathrm{~mL} / \mathrm{min})$ until irreducible water saturation $\left(S_{\mathrm{wi}}\right)$ was established. After $96 \mathrm{~h}$ of aging, the brine was injected at $0.2 \mathrm{~mL} / \mathrm{min}$ to displace the crude oil until water cut reached $95 \%$, and then the polymer solution was injected at $0.2 \mathrm{~mL} / \mathrm{min}$ to obtain water cut $95 \%$ once more. The EOR of polymer solutions is calculated with the following equation:

$$
\mathrm{EOR}=E-E_{\mathrm{w}},
$$

where EOR is enhanced oil recovery of polymer solution, \%; $E$ is the oil recovery of water flooding and polymer flooding process, \%; $E_{\mathrm{w}}$ is the oil recovery of water flooding process, $\%$.

All core flooding experiments were conducted at $80^{\circ} \mathrm{C}$. The maximum work pressure of the ISCO pump is $50 \mathrm{MPa}$, and its maximum and minimum displacement rates are 50.000 and $0.001 \mathrm{~mL} / \mathrm{min}$, respectively. The pressure drop was recorded by a pressure sensor with a precision of $\pm 0.0001 \mathrm{MPa}$. And flow chart of the core flooding tests is shown in Figure 1.

\section{Results and Discussion}

3.1. IR Spectra Analysis. The structures of the dendrite functional monomer and hyperbranched polymer were confirmed by IR spectra as illustrated in Figure 2. The dendrite functional monomer, which was prepared using EDA, methyl acrylate, and maleic anhydride, was confirmed by strong absorptions at $3383.78 \mathrm{~cm}^{-1}$ (-NH stretching vibration), $2949.63 \mathrm{~cm}^{-1} \quad\left(-\mathrm{CH}_{2}\right.$ stretching vibration), $1646.91 \mathrm{~cm}^{-1}$ $(\mathrm{C}=\mathrm{O}$ stretching vibration and carbon double-bond stretching vibration), and $1554.98 \mathrm{~cm}^{-1}$ (C-N stretching vibration and $-\mathrm{NH}$ bending vibration) in the IR spectroscopy of the dendrite functional monomer. Pure NVP exhibited a very strong absorption at $1703.01 \mathrm{~cm}^{-1}$, which reflected the carbonyl stretching; at $1629.32 \mathrm{~cm}^{-1}$, which was a carbon doublebond stretching vibration; and at $1445.11 \mathrm{~cm}^{-1}$, which was the characteristic absorption peak of NVP. The characteristic absorptions of the dendrite functional monomer and NVP were clearly presented, and the carbon double-bond was not detected in the IR spectroscopy of the hyperbranched polymer. As expected, the IR spectra demonstrated that the hyperbranched polymer was successfully synthesized. 


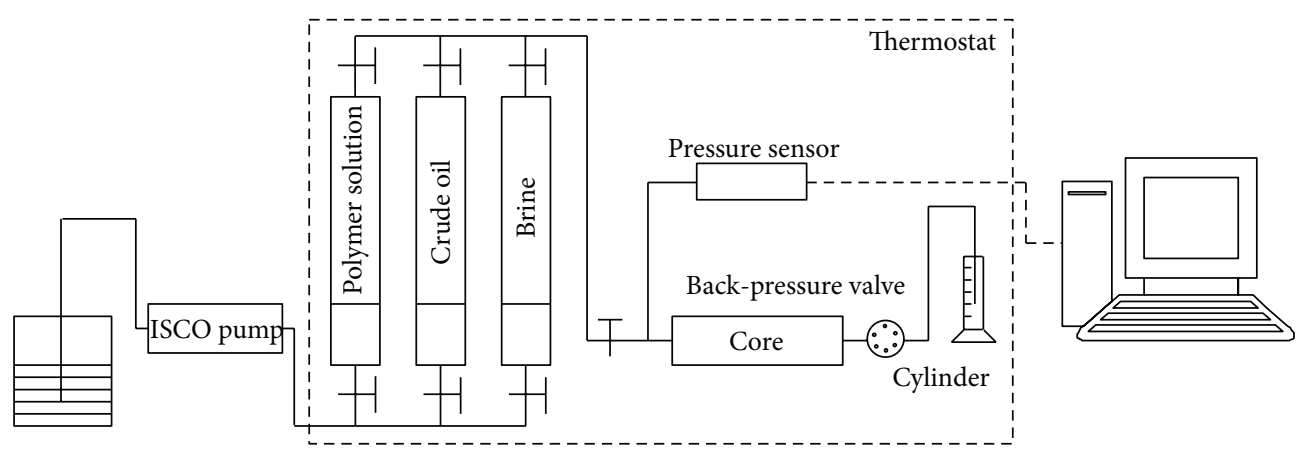

FIgURE 1: Flow chart of the core flooding tests.

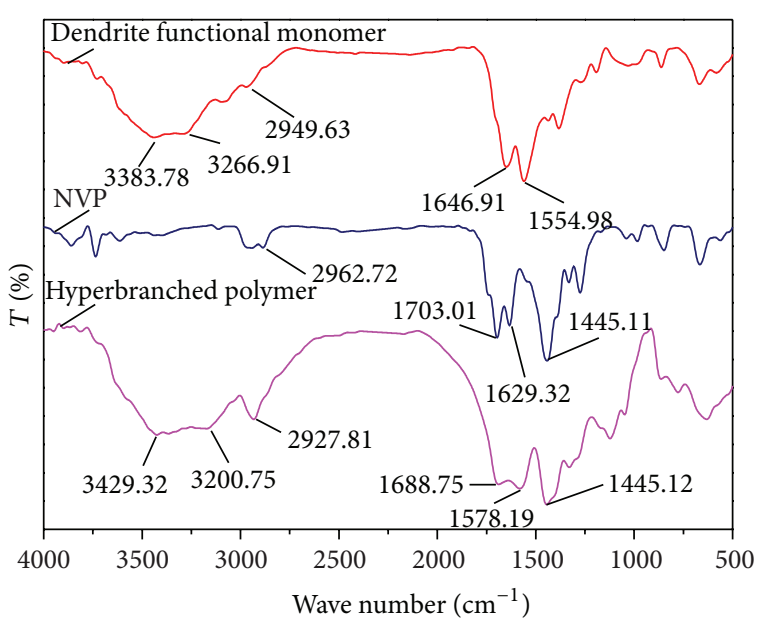

FIGURE 2: IR spectra of the dendrite functional monomer, NVP, and hyperbranched polymer.

3.2. ${ }^{1} \mathrm{H} N M R$ and ${ }^{13} \mathrm{C}$ NMR Analyses. The ${ }^{1} \mathrm{H}$ NMR spectrum and ${ }^{13} \mathrm{C}$ NMR spectrum of the dendrite functional monomer are shown in Figures 3(a) and 3(b), respectively. In Figure 3(a), the chemical shift value at $2.44 \mathrm{ppm}$ is assigned to the $-\mathrm{CH}_{2}-\mathrm{CH}_{2}-\mathrm{C}(\mathrm{O})-\mathrm{NH}-$ protons. The chemical shift value at $2.60 \mathrm{ppm}$ is due to the $-\mathrm{CH}_{2}-\mathrm{N}\left(\mathrm{CH}_{2}-\mathrm{CH}_{2}-\mathrm{C}(\mathrm{O})-\right)_{2}$ protons. The $-\mathrm{CH}_{2}-\mathrm{CH}_{2}-\mathrm{C}(\mathrm{O})-\mathrm{NH}-$ protons appear at $2.79 \mathrm{ppm}$. The chemical shift value at $3.04 \mathrm{ppm}$ is assigned to the $-\mathrm{NH}-\mathrm{CH}_{2}-\mathrm{CH}_{2}-$ protons. The $-\mathrm{NH}-\mathrm{CH}_{2}-\mathrm{CH}_{2}-$ protons appear at $3.42 \mathrm{ppm}$. The chemical shift value at $5.95 \mathrm{ppm}$ is due to the $-\mathrm{C}(\mathrm{O})-\mathrm{CH}=\mathrm{CH}-\mathrm{C}(\mathrm{O})-$ protons. In Figure $3(\mathrm{~b})$, the chemical shift value at $171.11 \mathrm{ppm}$ is due to $\mathrm{C}_{6}$. The chemical shift value at $164.96 \mathrm{ppm}$ belongs to $\mathrm{C}_{5}$. The chemical shift value at $134.49 \mathrm{ppm}$ is due to $\mathbf{C}_{4}$. The characteristic peak at $48.88 \mathrm{ppm}$ belongs to $\mathbf{C}_{3}$. The characteristic peak at $36.90 \mathrm{ppm}$ is due to $\mathbf{C}_{2}$. The chemical shift value at $31.01 \mathrm{ppm}$ is assigned to $\mathrm{C}_{\mathbf{1}}$. The results of ${ }^{1} \mathrm{H}$ NMR spectrum and ${ }^{13} \mathrm{C}$ NMR spectrum showed that the dendrite functional monomer was synthesized.

The ${ }^{1} \mathrm{H}$ NMR spectrum and ${ }^{13} \mathrm{C}$ NMR spectrum of the hyperbranched polymer are shown in Figures 4(a) and 4(b), respectively. In Figure 4(a), the chemical shift value at $3.23 \mathrm{ppm}$ is due to the $-\mathrm{NH}-\mathrm{CH}_{2}-\mathrm{CH}_{2}-$ protons and the $-\mathrm{C}(\mathrm{O})-\mathrm{CH}_{2}-\mathrm{CH}_{2}-\mathrm{CH}_{2}-$ protons. The chemical shift value at $2.65 \mathrm{ppm}$ is assigned to the $-\mathrm{CH}_{2}-\mathrm{N}\left(\mathrm{CH}_{2}-\mathrm{CH}_{2}-\right.$ $\mathrm{C}(\mathrm{O})-)_{2}$ protons. The $-\mathrm{CH}_{2}-\mathrm{CH}_{2}-\mathrm{C}(\mathrm{O})-\mathrm{NH}-$ protons and the $-\mathrm{CH}(\mathrm{C}(\mathrm{O})-)-\mathrm{CH}(\mathrm{C}(\mathrm{O})-)-$ protons appear at $2.49 \mathrm{ppm}$. The chemical shift value at $2.16 \mathrm{ppm}$ is assigned to the $-\mathrm{C}(\mathrm{O})-\mathrm{CH}_{2}-\mathrm{CH}_{2}-\mathrm{CH}_{2}-$ protons, the $-\mathrm{CH}_{2}-\mathrm{CH}_{2}-\mathrm{C}(\mathrm{O})-$ $\mathrm{NH}-$ protons, and the $-\mathrm{CH}_{2}-$ protons which are obtained from the carbon double-bonds of AM, AA, and NVP. The $-\mathrm{CH}-$ protons, which are free radical polymerization products of the carbon double-bonds of AM, AA, and NVP, appear at $1.54 \mathrm{ppm}$. In Figure 4(b), the chemical shift value at $182.96 \mathrm{ppm}$ belongs to $\mathrm{C}_{8}$. The chemical shift value at $179.79 \mathrm{ppm}$ is due to $\mathbf{C}_{7}$. The chemical shift value at $178.63 \mathrm{ppm}$ is assigned to $\mathbf{C}_{6}$. The chemical shift value at $44.80 \mathrm{ppm}$ is due to $\mathrm{C}_{5}$. The characteristic peak at $42.30 \mathrm{ppm}$ belongs to $\mathbf{C}_{4}$. The characteristic peak from 35.11 to $36.95 \mathrm{ppm}$ is due to $\mathbf{C}_{3}$. The chemical shift value at $31.80 \mathrm{ppm}$ is assigned to $\mathrm{C}_{2}$. And the characteristic peak of $\mathrm{C}_{1}$ is observed at $17.62 \mathrm{ppm} .{ }^{1} \mathrm{H}$ NMR spectrum and ${ }^{13} \mathrm{C}$ NMR spectrum indicated that the hyperbranched polymer was successfully synthesized.

The ${ }^{1} \mathrm{H}$ NMR spectrum and ${ }^{13} \mathrm{C}$ NMR spectrum of HPAM are shown in Figures 5(a) and 5(b), respectively. In Figure 5(a), the chemical shift value at $2.12 \mathrm{ppm}$ is assigned to the $-\mathrm{CH}-\mathrm{CH}_{2}-$ protons. The characteristic peak of the $-\mathrm{CH}-\mathrm{CH}_{2}-$ protons appears at $1.55 \mathrm{ppm}$. In Figure 5(b), the chemical shift value at $183.12 \mathrm{ppm}$ belongs to $\mathbf{C}_{4}$. The chemical shift value at $179.58 \mathrm{ppm}$ is due to $\mathbf{C}_{\mathbf{3}}$. The characteristic peak at $41.95 \mathrm{ppm}$ belongs to $\mathbf{C}_{2}$. The chemical shift value at $34.99 \mathrm{ppm}$ is assigned to $\mathbf{C}_{\mathbf{1}}$.

3.3. Elemental Analysis of the Hyperbranched Polymer and HPAM. The elemental analysis of the hyperbranched polymer and HPAM was carried out by Vario EL III elemental analyzer. The content of different elements can be calculated by detecting the gases, which are the decomposition products of these copolymers at high temperature. Theoretical values of the hyperbranched polymer are $50.49 \%(\mathrm{C} \%), 6.53 \%(\mathrm{H} \%), 30.12 \%(\mathrm{O} \%)$, and $12.86 \%(\mathrm{~N} \%)$; found values of the hyperbranched polymer are $45.46 \%$ (C\%), 6.12\% (H\%), 26.73\% (O\%), and $11.36 \%(\mathrm{~N} \%)$. Theoretical values of HPAM are $50.50 \%(\mathrm{C} \%), 6.60 \%(\mathrm{H} \%)$, $29.03 \%(\mathrm{O} \%)$, and $13.87 \%(\mathrm{~N} \%)$; found values of HPAM 


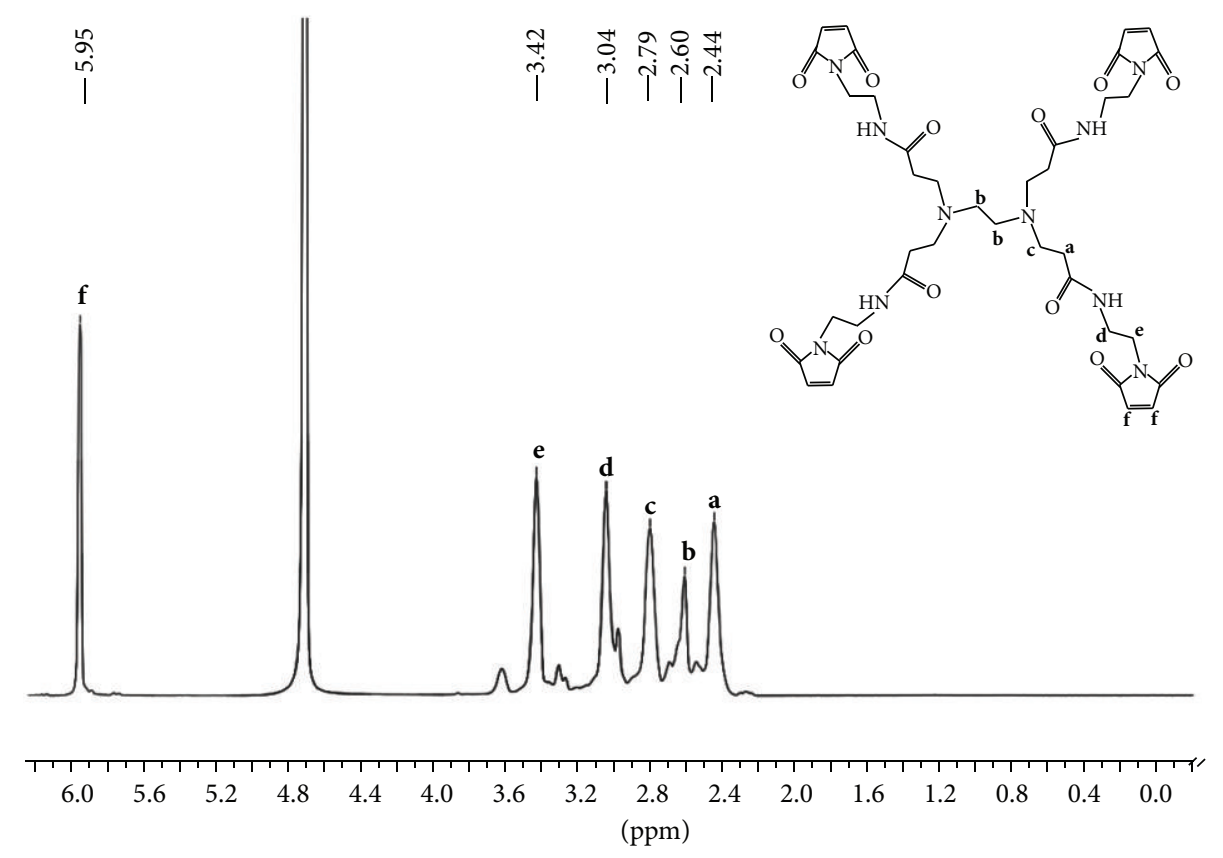

(a)

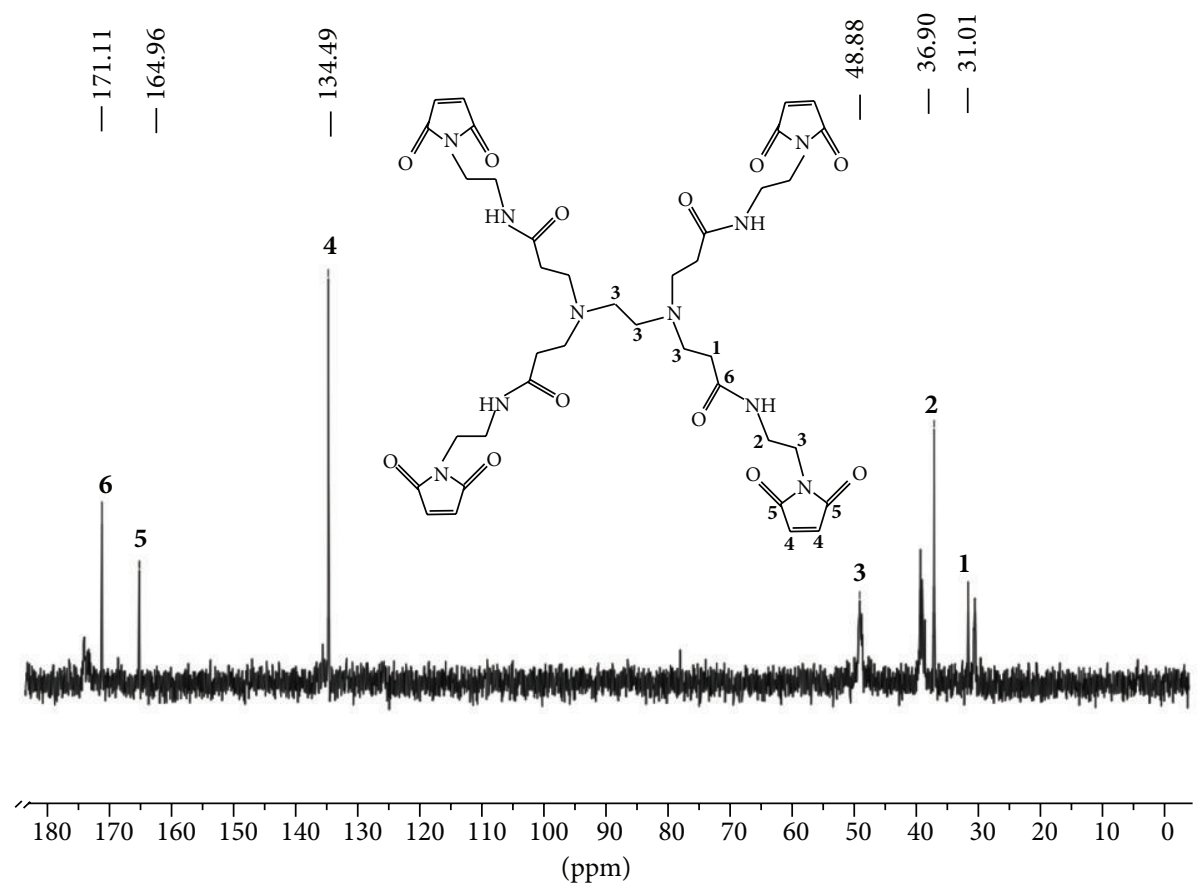

(b)

FIgURE 3: (a) ${ }^{1} \mathrm{H}$ NMR spectrum of the dendrite functional monomer in $\mathrm{D}_{2} \mathrm{O}$; (b) ${ }^{13} \mathrm{C}$ NMR spectrum of the dendrite functional monomer in $\mathrm{D}_{2} \mathrm{O}$.

are $45.91 \%(\mathrm{C} \%), 6.04 \%(\mathrm{H} \%), 26.19 \%(\mathrm{O} \%)$, and $12.03 \%$ $(\mathrm{N} \%)$.

3.4. Microscopic Structure Analysis by SEM. The microscopic structures of the HPAM and hyperbranched polymer solutions $(2000 \mathrm{mg} / \mathrm{L})$ prepared with distilled water were observed through SEM at room temperature. Among these images, Figures 6(a)-6(c) are HPAM solutions at different scan sizes $(20 \mu \mathrm{m}, 5000 \mathrm{x} ; 10 \mu \mathrm{m}, 10000 \mathrm{x} ; 5 \mu \mathrm{m}, 20000 \mathrm{x}$, resp.). Similarly, the images of hyperbranched polymer solutions are shown in Figure 6(d) $(20 \mu \mathrm{m}, 5000 x)$, Figure 6(e) $(10 \mu \mathrm{m}, 10000 \mathrm{x})$, and Figure $6(\mathrm{f})(5 \mu \mathrm{m}, 20000 \mathrm{x})$. As shown in Figure 6 , it could be obviously observed that there were space net structures in the images of the hyperbranched polymer 


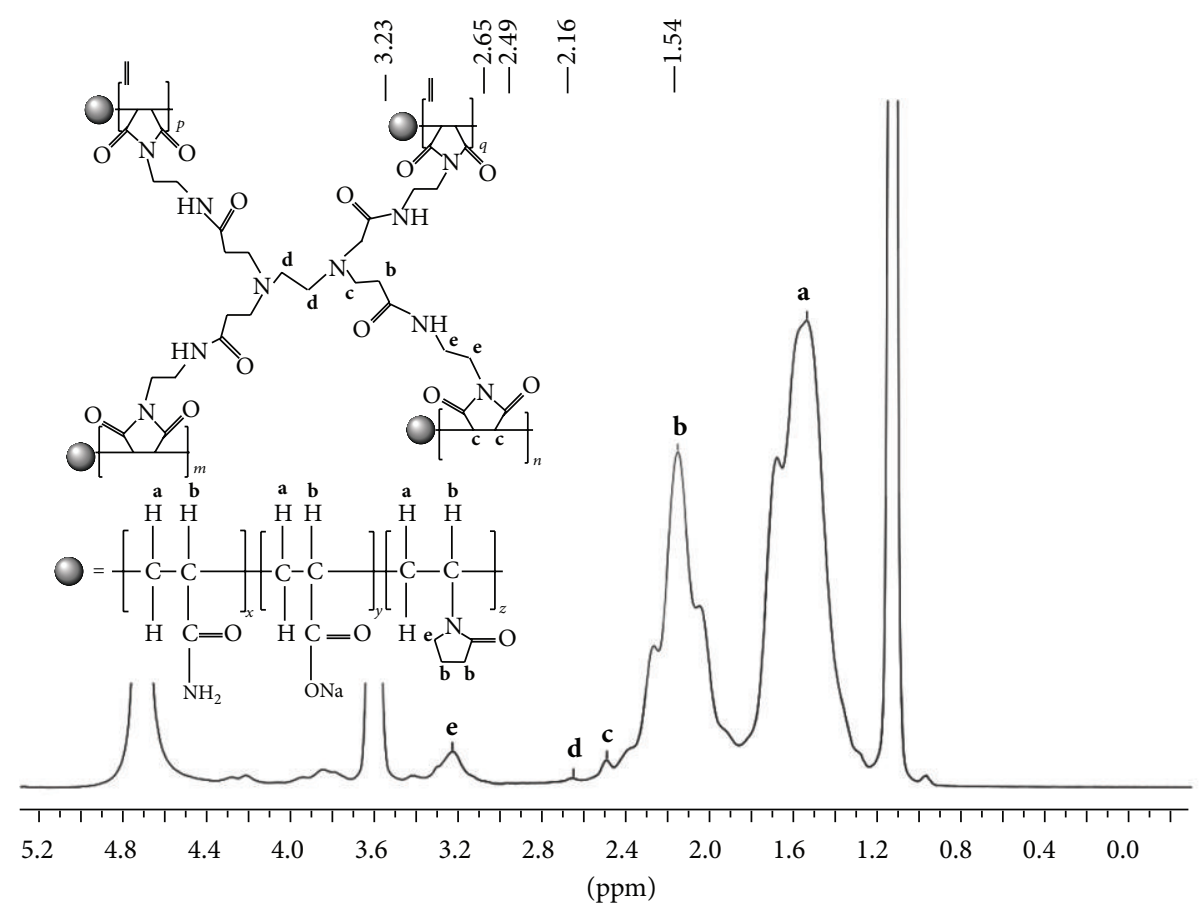

(a)

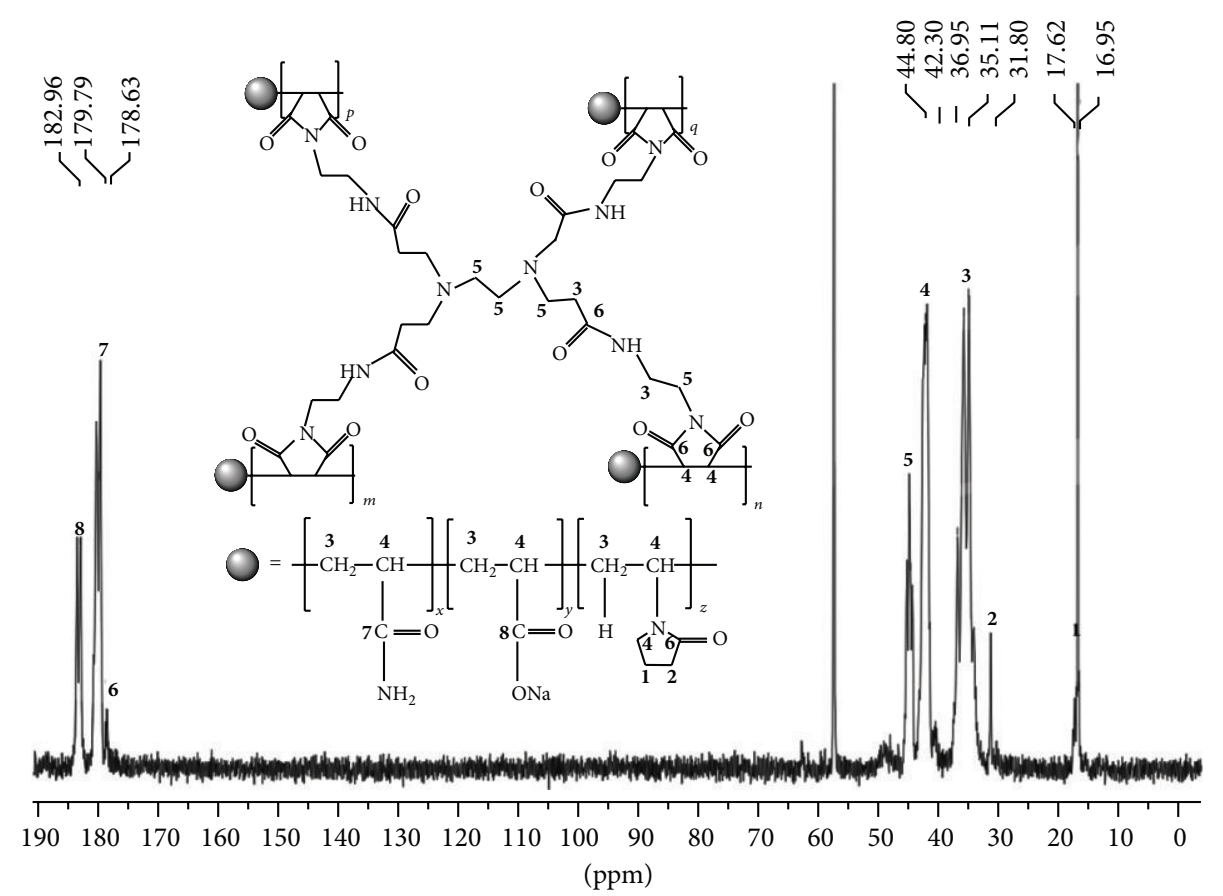

(b)

Figure 4: (a) ${ }^{1} \mathrm{H}$ NMR spectrum of the hyperbranched polymer in $\mathrm{D}_{2} \mathrm{O}$; (b) ${ }^{13} \mathrm{C}$ NMR spectrum of the hyperbranched polymer in $\mathrm{D}_{2} \mathrm{O}$.

solutions. Moreover, it could be found that the microscopic reticular structures of the hyperbranched polymer solutions were much more compact than those of HPAM solutions in the same scan size. The much denser networks of the hyperbranched polymer solutions may help to reduce the effect of shear on the hyperbranched polymer molecular chain and improve the viscosity retention rate of the hyperbranched polymer at high shear rate.

3.5. Weight-Average Molecular Weight. $2 \mathrm{mg} / \mathrm{L}$ copolymer solution was prepared using distilled water and filtered by a $0.5 \mu \mathrm{m}$ Millipore Millex-LCR filter. As shown in Figure 7, 


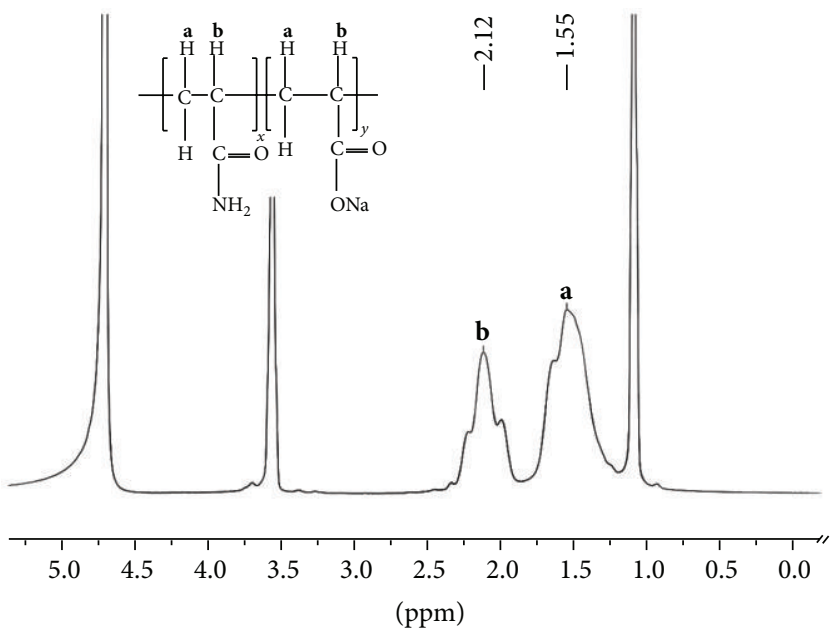

(a)

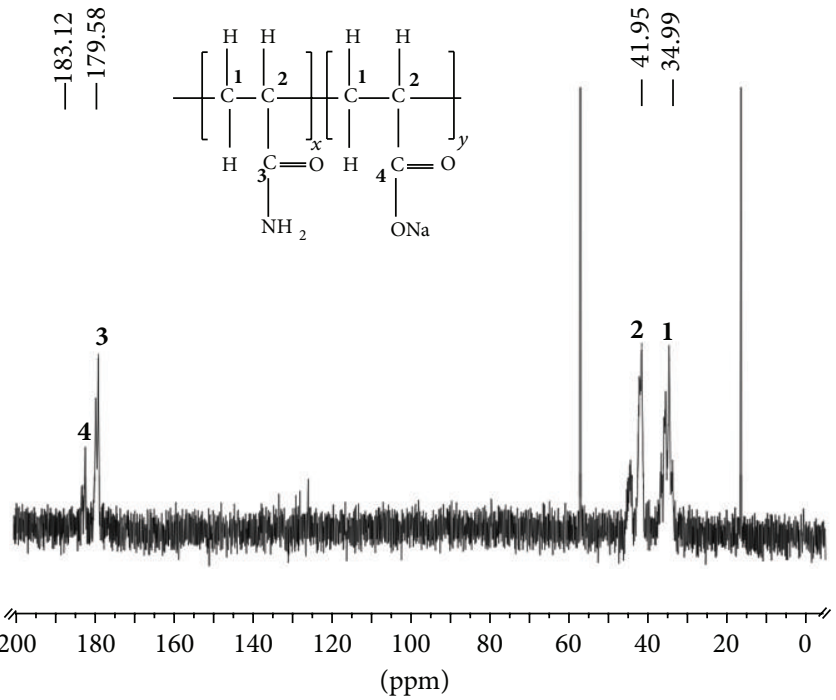

(b)

Figure 5: (a) ${ }^{1} \mathrm{H}$ NMR spectrum of HPAM in $\mathrm{D}_{2} \mathrm{O}$; (b) ${ }^{13} \mathrm{C}$ NMR spectrum of HPAM in $\mathrm{D}_{2} \mathrm{O}$.

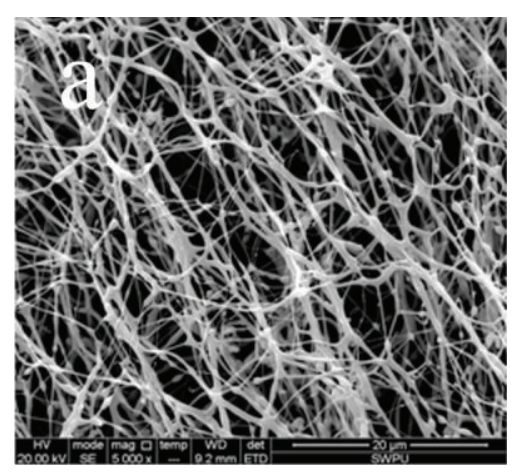

(a)

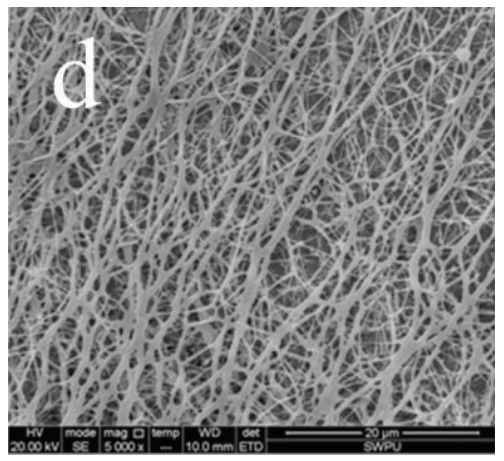

(d)

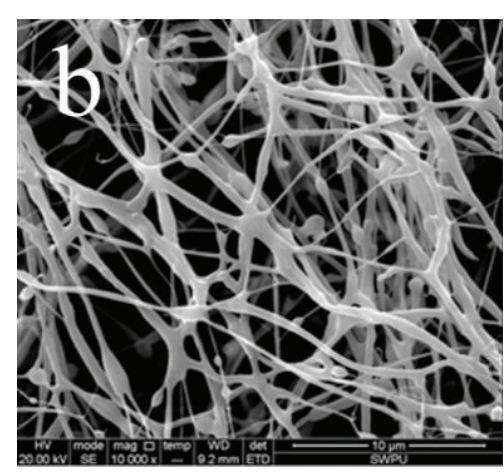

HPAM

(b)

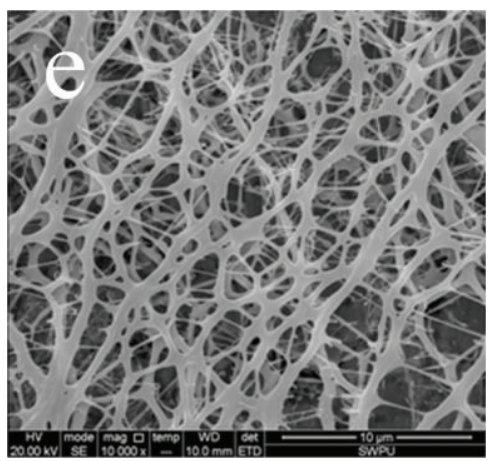

Hyperbranched polymer

(e)

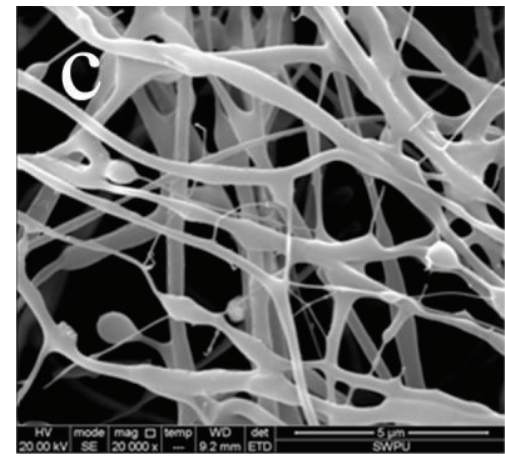

(c)

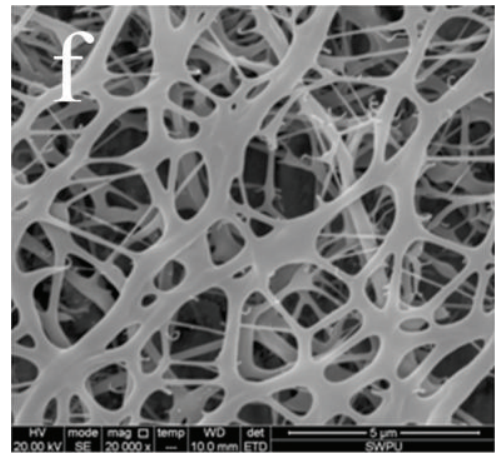

(f)

Figure 6: SEM images of HPAM and hyperbranched polymer: (a) HPAM solution at $20 \mu \mathrm{m}, 5000 \mathrm{x}$; (b) HPAM solution at $10 \mu \mathrm{m}$, $10000 \mathrm{x}$; (c) HPAM solution at $5 \mu \mathrm{m}, 20000 \mathrm{x}$; (d) hyperbranched polymer solution at $20 \mu \mathrm{m}, 5000 \mathrm{x}$; (e) hyperbranched polymer solution at $10 \mu \mathrm{m}$, 10000x; (f) hyperbranched polymer solution at $5 \mu \mathrm{m}, 20000 \mathrm{x}$. 
TABLE 2: The parameters of cores and the results of core flooding tests.

\begin{tabular}{lccccccccc}
\hline Polymer & Cores & $\begin{array}{c}\text { Length } \\
(\mathrm{cm})\end{array}$ & $\begin{array}{c}\text { Diameter } \\
(\mathrm{cm})\end{array}$ & $\begin{array}{c}\text { Porosity } \\
(\%)\end{array}$ & $\begin{array}{c}\text { Permeability } \\
(\mathrm{mD})\end{array}$ & $\begin{array}{c}S_{\mathrm{wi}} \\
(\%)\end{array}$ & $\begin{array}{c}E \\
(\%)\end{array}$ & $\begin{array}{c}E_{\mathrm{w}} \\
(\%)\end{array}$ & $\begin{array}{c}\text { EOR } \\
(\%)\end{array}$ \\
\hline HPAM & $1 \#$ & 8.95 & 3.79 & 23.75 & 985.28 & 20.42 & 47.63 & 30.97 & 16.67 \\
Hyperbranched polymer & $2 \#$ & 8.87 & 3.78 & 23.69 & 980.15 & 20.16 & 54.33 & 30.82 & 23.51 \\
\hline
\end{tabular}

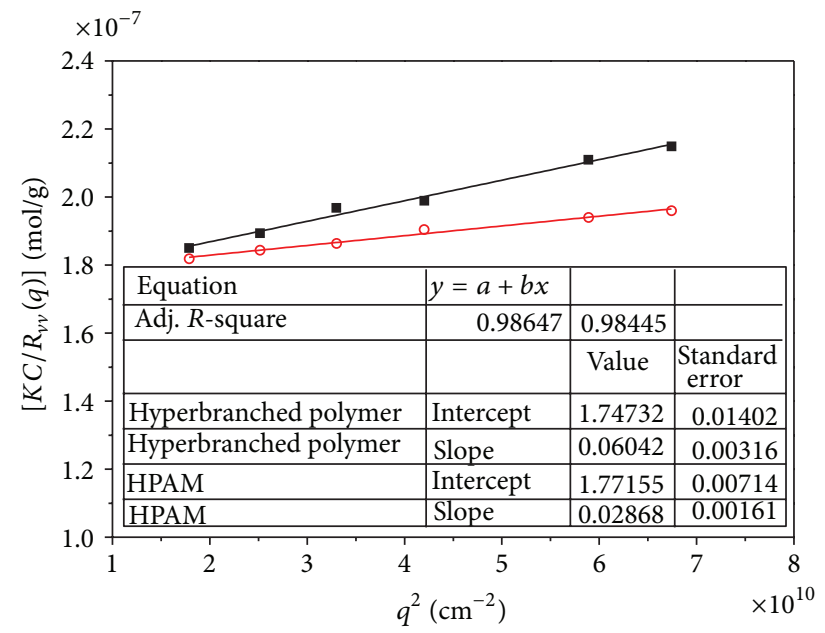

- Hyperbranched polymer

- HPAM

— Linear fit of hyperbranched polymer — Linear fit of HPAM

FIGURE 7: KC/ $R_{v v}(q)$ versus $q^{2}$ for the hyperbranched polymer and HPAM.

the weight -average molecular weight of the hyperbranched polymer and HPAM was 5.72 and $5.64 \times 10^{6} \mathrm{~g} / \mathrm{mol}$, respectively. The hyperbranched polymer has higher weight-average molecular weight than HPAM due to its hyperbranched structure.

3.6. Temperature-Resistance. The apparent viscosity versus temperature curves of the hyperbranched polymer and HPAM solutions is shown in Figure 8. Compared with HPAM, the hyperbranched polymer displayed better temperature-resistance (apparent viscosity: $558.6 \mathrm{mPa} \cdot \mathrm{s}$ versus $260.3 \mathrm{mPa} \cdot \mathrm{s}$ and viscosity retention rate: $45.01 \%$ versus $22.12 \%$ ) at $95^{\circ} \mathrm{C}$. This phenomenon may be explained by the inelasticity structure of pyrrole ring which can improve the thermal stability of the hyperbranched polymer.

3.7. Salt-Resistance. The influences of salt $\left(\mathrm{NaCl}, \mathrm{CaCl}_{2}\right.$, or $\mathrm{MgCl}_{2} \cdot 6 \mathrm{H}_{2} \mathrm{O}$ ) on apparent viscosity of the HPAM and hyperbranched polymer solutions were carried out at $20^{\circ} \mathrm{C}$. As shown in Figures 9(a)-9(c), with the increase of salt concentration $\left(\mathrm{NaCl}, \mathrm{CaCl}_{2}\right.$, or $\left.\mathrm{MgCl}_{2} \cdot 6 \mathrm{H}_{2} \mathrm{O}\right)$, the apparent viscosity of HPAM solutions decreased rapidly, and then it is kept at a low value. Similarly, the measure of the hyperbranched polymer solutions displayed similar phenomena. However, compared with HPAM solution, the hyperbranched polymer solutions displayed better antisalt due to higher apparent viscosity under the same conditions. These results

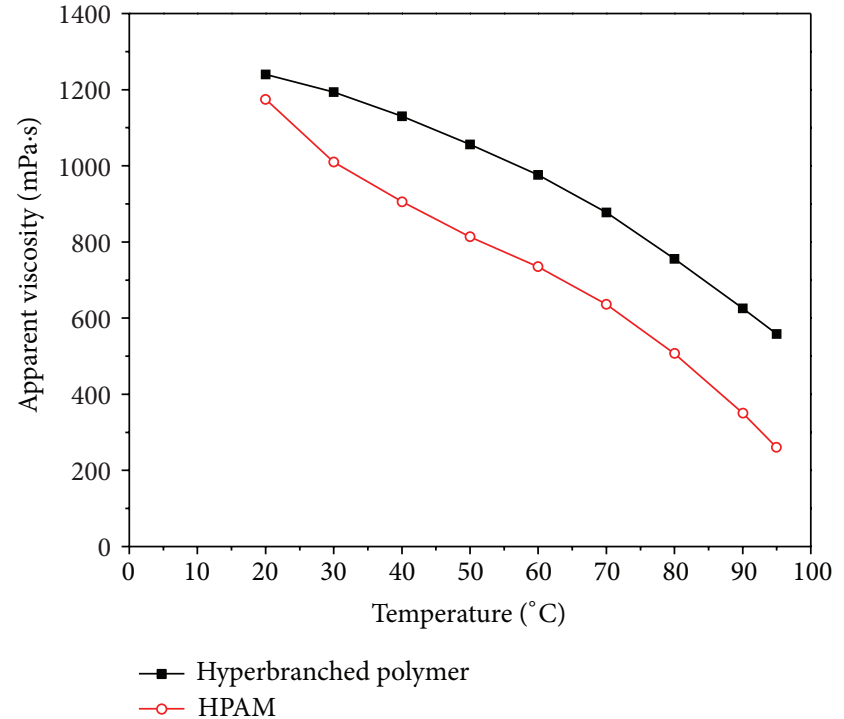

FIGURE 8: Apparent viscosity versus temperature for HPAM and hyperbranched polymer solutions $(5000 \mathrm{mg} / \mathrm{L})$.

reveal that the hyperbranched polymer can withstand higher salt concentration than HPAM. This characteristic may be well explained by the special network structure which can enhance the interaction between the hyperbranched polymer chains, and crimping degree of the polymeric chains will be smaller than HPAM at the same salt concentration. Thus the hyperbranched polymer exhibits higher apparent viscosity and retention rates.

3.8. Shear-Resistance. Shear-resistance of the polymer solutions was conducted on HAAKE RS 6000 rotational rheometer at $80^{\circ} \mathrm{C}$ by changing the shear rate from $170 \mathrm{~s}^{-1}$ to $500 \mathrm{~s}^{-1}$ and from $500 \mathrm{~s}^{-1}$ to $170 \mathrm{~s}^{-1}$ around. As shown in Figure 10, the viscosity retention rate of the HPAM and the hyperbranched polymer was $61.95 \%$ and $91.64 \%$, respectively, when one cycle was completed. The phenomena may support the microscopic reticular structures of the hyperbranched polymer which can reduce the effect of shear on the hyperbranched polymer molecular chain during shear process and restore the structures of the hyperbranched polymer after being sheared.

3.9. Enhanced Oil Recovery. As shown in Table 2, the EOR of the hyperbranched polymer solutions and HPAM solutions was $23.51 \%$, and $16.67 \%$, respectively. This phenomenon may support higher viscosity retention rate of the hyperbranched polymer contributes to expand injection water sweeping volume and enhance oil recovery. As shown in Figure 11, 


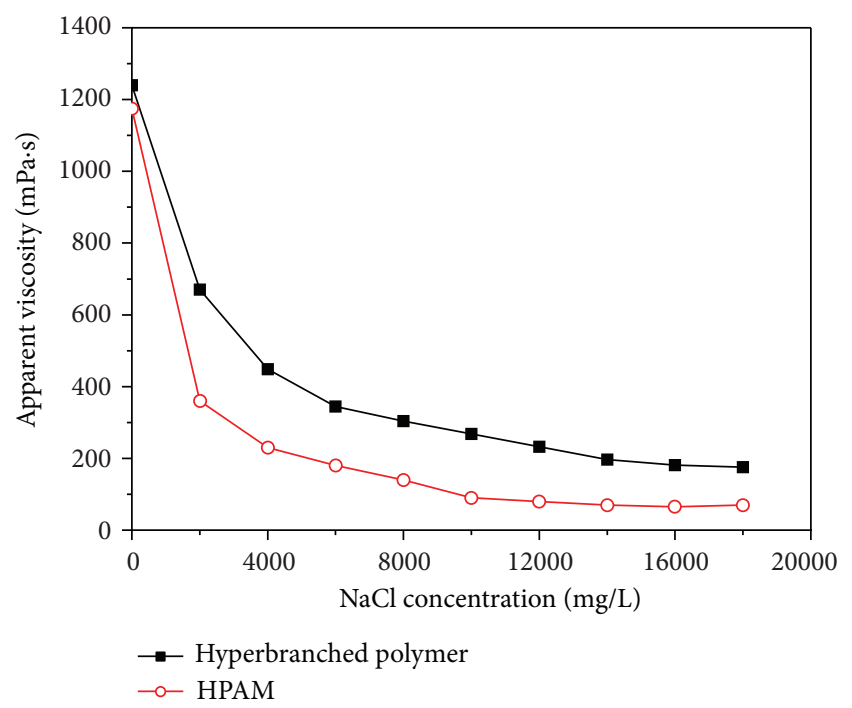

(a)

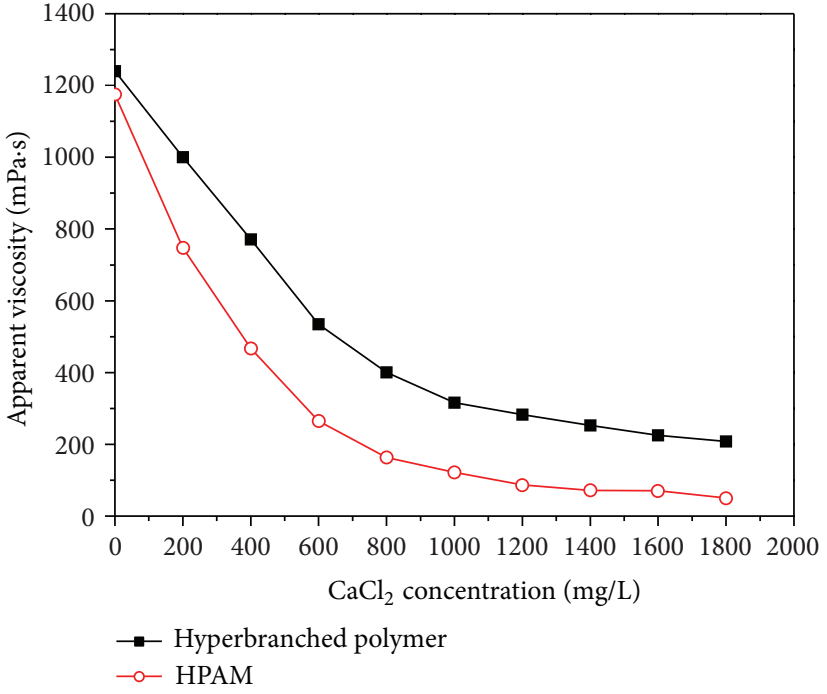

(b)

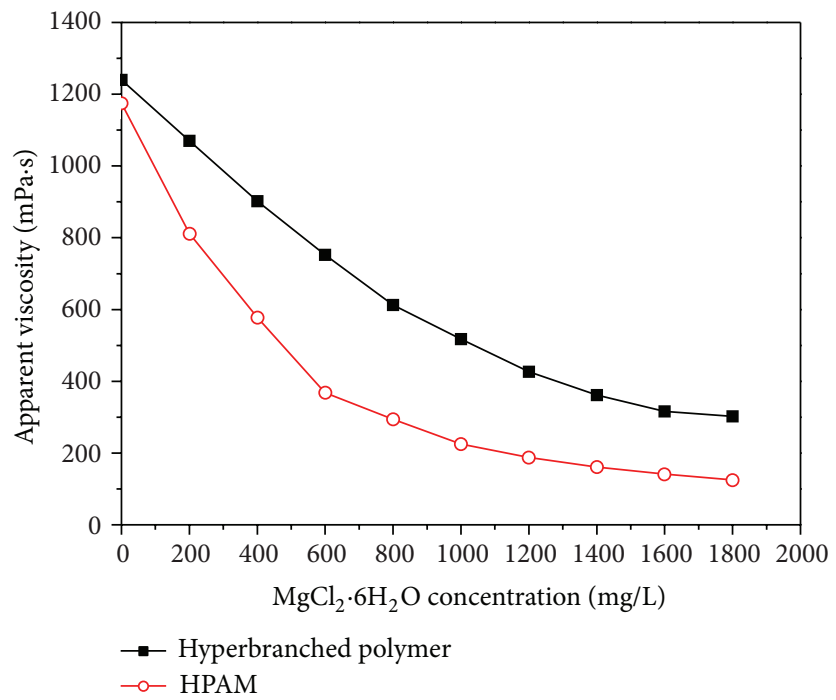

(c)

Figure 9: Salt-resistance ((a) $\mathrm{NaCl}$, (b) $\mathrm{CaCl}_{2}$, and (c) $\mathrm{MgCl}_{2} \cdot 6 \mathrm{H}_{2} \mathrm{O}$ ) of $\mathrm{HPAM}$ and hyperbranched polymer solutions (5000 mg/L) at $20^{\circ} \mathrm{C}$.

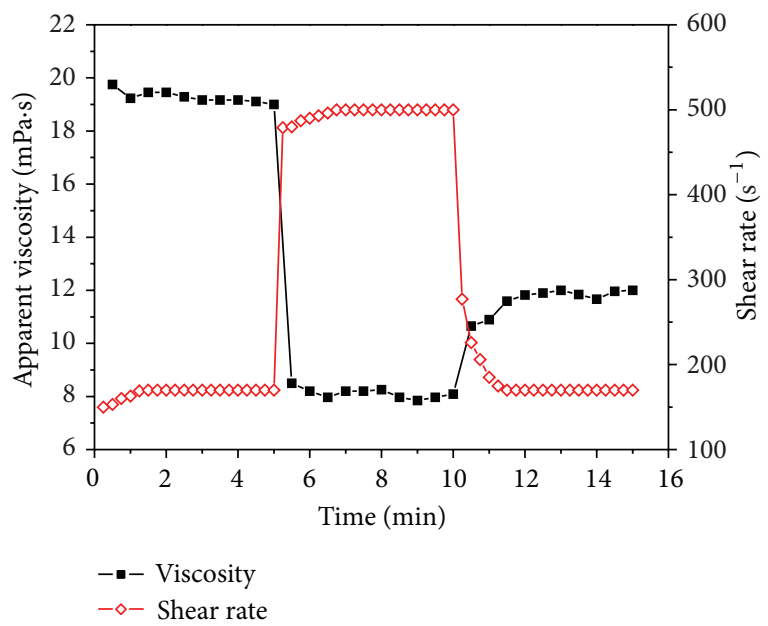

(a)

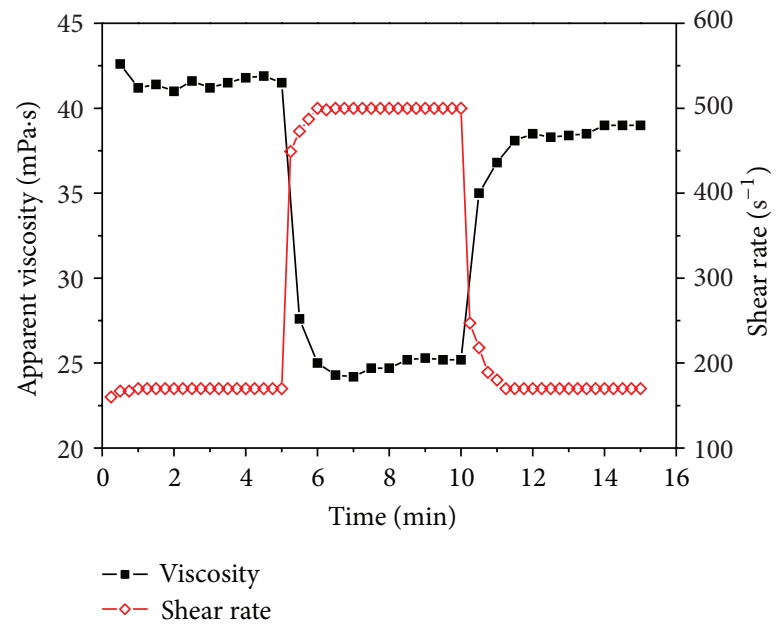

(b)

Figure 10: Shear-resistance of HPAM (a) and hyperbranched polymer (b) at $80^{\circ} \mathrm{C}(5000 \mathrm{mg} / \mathrm{L})$. 


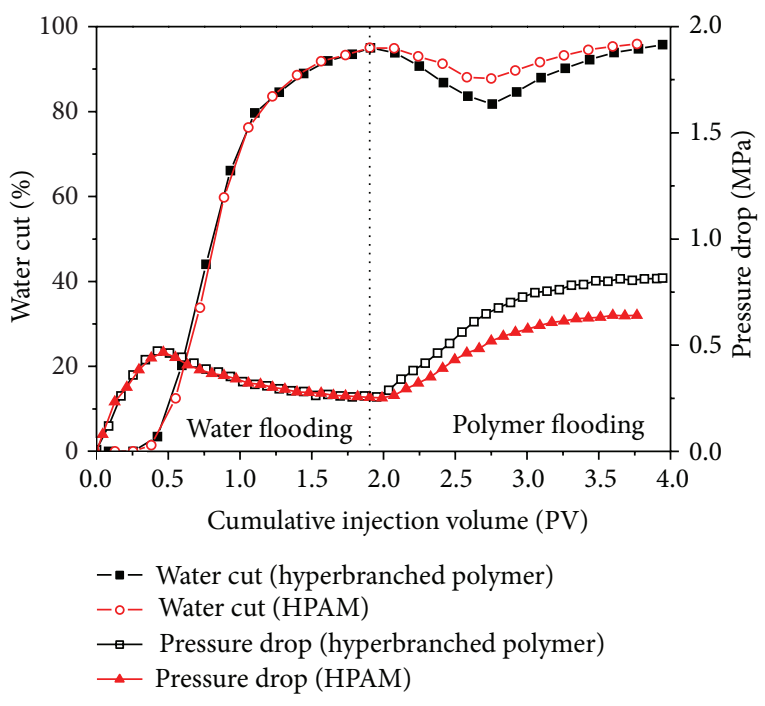

FIGURE 11: EOR results of the HPAM and hyperbranched polymer solutions at $80^{\circ} \mathrm{C}$.

compared with HPAM, the hyperbranched polymer revealed stronger ability of establishing flow resistance and reducing water cut in polymer flooding. This phenomenon may support the sweep efficiency which is obviously improved by the hyperbranched polymer due to its excellent temperatureresistance, salt-resistance, and shear-resistance.

\section{Conclusions}

A novel hyperbranched polymer possessing microscopic reticular structure was successfully synthesized using AM, AA, NVP, and dendrite functional monomer as raw materials under mild conditions. Compared with HPAM, the hyperbranched polymer exhibits obvious advantages in temperature-resistance, salt-resistance, and shear-resistance due to the introduction of pyrrole ring which can reduce the influence of high temperature on the polymer molecular chain and the introduction of the reticular structures which can be favorable to decrease the crimping degree of polymeric chains under high shear rate and high salinity. Thus, the EOR capability of the hyperbranched polymer is improved remarkably even in a harsh condition.

\section{Conflict of Interests}

The authors declare no possible conflict of interests.

\section{Acknowledgments}

This work was financially supported by the Open Fund (PLN1212) of State Key Laboratory of Oil and Gas Reservoir Geology and Exploitation (Southwest Petroleum University), the Specialized Research Fund for the Doctoral Program of Higher Education (20125121120011), the Key Program for Undergraduate Extracurricular Open Experiment (KSZ1246/KSZ1247) of Southwest Petroleum University, and the Cultivation Project of Sichuan Province Science and Technology Innovation Seedling Project (20132060).

\section{References}

[1] N. Mungan, F. W. Smith, J. L. Thompson, O. Sinclair, and C. Gas, "Some aspects of polymer floods," Journal of Petroleum Technology, vol. 18, no. 9, pp. 1143-1150, 1966.

[2] G. Li, L. Zhai, G. Xu, Q. Shen, H. Mao, and M. Pei, "Current Tertiary oil recovery in China," Journal of Dispersion Science and Technology, vol. 21, no. 4, pp. 367-408, 2000.

[3] T. Masuda, S.-I. Yamamoto, O. Moriya, M. Kashio, and T. Sugizaki, "Preparation of stimuli-responsive polysilsesquioxane grafted block copolymer of acrylamide monomers," Polymer Journal, vol. 40, no. 2, pp. 126-136, 2008.

[4] B. Yadali Jamaloei, R. Kharrat, and F. Torabi, "Analysis and correlations of viscous fingering in low-tension polymer flooding in heavy oil reservoirs," Energy and Fuels, vol. 24, no. 12, pp. 6384-6392, 2010.

[5] L. Shi, Z. Ye, Z. Zhang, C. Zhou, S. Zhu, and Z. Guo, "Necessity and feasibility of improving the residual resistance factor of polymer flooding in heavy oil reservoirs," Petroleum Science, vol. 7, no. 2, pp. 251-256, 2010.

[6] D. A. Z. Wever, F. Picchioni, and A. A. Broekhuis, "Polymers for enhanced oil recovery: a paradigm for structure-property relationship in aqueous solution," Progress in Polymer Science, vol. 36, no. 11, pp. 1558-1628, 2011.

[7] Z. Q. Guo, M. Z. Dong, Z. X. Chen, and J. Yao, "Dominant scaling groups of polymer flooding for enhanced heavy oil recovery," Industrial \& Engineering Chemistry Research, vol. 52, no. 2, pp. 911-921, 2013.

[8] S. H. Chang and I. J. Chung, "Effect of shear flow on polymer desorption and latex dispersion stability in the presence of adsorbed polymer," Macromolecules, vol. 24, no. 2, pp. 567-571, 1991.

[9] T. Rho, J. Park, C. Kim, H.-K. Yoon, and H.-S. Suh, "Degradation of polyacrylamide in dilute solution," Polymer Degradation and Stability, vol. 51, no. 3, pp. 287-293, 1996.

[10] L. Xue, U. S. Agarwal, and P. J. Lemstra, "Shear degradation resistance of star polymers during elongational flow," Macromolecules, vol. 38, no. 21, pp. 8825-8832, 2005.

[11] R. Zhang, Z. Ye, L. Peng, N. Qin, Z. Shu, and P. Luo, "The shearing effect on hydrophobically associative water-soluble polymer and partially hydrolyzed polyacrylamide passing through wellbore simulation device," Journal of Applied Polymer Science, vol. 127, no. 1, pp. 682-689, 2013.

[12] Z. B. Ye, G. J. Gou, S. H. Gou, W. C. Jiang, and T. Y. Liu, "Synthesis and characterization of a water-soluble sulfonates copolymer of acrylamide and N-Allylbenzamide as enhanced oil recovery chemical," Journal of Applied Polymer Science, vol. 128, no. 3, pp. 2003-2011, 2013.

[13] A. Sabhapondit, A. Borthakur, and I. Haque, "Water soluble acrylamidomethyl propane sulfonate (AMPS) copolymer as an enhanced oil recovery chemical," Energy and Fuels, vol. 17, no. 3, pp. 683-688, 2003.

[14] C.-S. Yang, K. Shin, and H. K. Jeong, "Thermal analysis of poly(sodium 4-styrenesulfonate) intercalated graphite oxide composites," Chemical Physics Letters, vol. 517, no. 4-6, pp. 196198, 2011.

[15] X.-J. Liu, W.-C. Jiang, S.-H. Gou, Z.-B. Ye, and X.-D. Xie, "Synthesis and evaluation of a water-soluble acrylamide binary 
sulfonates copolymer on MMT crystalline interspace and EOR," Journal of Applied Polymer Science, vol. 125, no. 2, pp. 1252-1260, 2012.

[16] X. J. Liu, W. C. Jiang, S. H. Gou, Z. B. Ye, and C. Luo, "Synthesis and clay stabilization of a water-soluble copolymer based on acrylamide, modular $\beta$-cyclodextrin, and AMPS," Journal of Applied Polymer Science, vol. 128, no. 5, pp. 3398-3404, 2012.

[17] X. J. Liu, W. C. Jiang, S. H. Gou et al., "Synthesis and evaluation of novel water-soluble copolymers based on acrylamide and modular $\beta$-cyclodextrin," Carbohydrate Polymers, vol. 96, pp. 47-56, 2013.

[18] D. A. Tomalia, H. Baker, J. Dewald et al., "New class of polymers: starburst-dendritic macromolecules," Polymer Journal, vol. 17, no. 1, pp. 117-132, 1984.

[19] D. A. Tomalia, H. Baker, J. Dewald et al., "Dendritic macromolecules: synthesis of starburst dendrimers," Macromolecules, vol. 19, no. 9, pp. 2466-2468, 1986.

[20] J. C. Hummelen, J. L. J. Van Dongen, and E. W. Meijer, "Electrospray mass spectrometry of poly(propylene imine) dendrimersThe issue of dendritic purity or polydispersity," Chemistry, vol. 3, no. 9, pp. 1489-1493, 1997.

[21] L. J. Twyman, A. E. Beezer, R. Esfand, M. J. Hardy, and J. C. Mitchell, "The synthesis of water soluble dendrimers, and their application as possible drug delivery systems," Tetrahedron Letters, vol. 40, no. 9, pp. 1743-1746, 1999.

[22] M. S. Diallo, S. Christie, P. Swaminathan et al., "Dendritic chelating agents. 1 . $\mathrm{Cu}(\mathrm{II})$ binding to ethylene diamine core poly(amidoamine) dendrimers in aqueous solutions," Langmuir, vol. 20, no. 7, pp. 2640-2651, 2004.

[23] L. Xue, U. S. Agarwal, M. Zhang et al., "Synthesis and direct topology visualization of high-molecular-weight star PMMA," Macromolecules, vol. 38, no. 6, pp. 2093-2100, 2005.

[24] D. S. Achilleos, T. K. Georgiou, and C. S. Patrickios, "Amphiphilic model conetworks based on cross-linked star copolymers of benzyl methacrylate and 2-(dimenthylamino) ethyl methacrylate: synthesis, characterization, and DNA adsorption studies," Biomacromolecules, vol. 7, no. 12, pp. 33963405, 2006.

[25] X. Y. Wang, Y. C. Zhang, T. F. Li, W. D. Tian, Q. Zhang, and Y. Y. Cheng, "Generation 9 polyamidoamine dendrimer encapsulated platinum nanoparticle mimics catalase size, shape, and catalytic activity," Langmuir, vol. 29, no. 17, pp. 5262-5270, 2013.

[26] X. Wang, X. Qiu, and C. Wu, "Comparison of the coil-toglobule and the globule-to-coil transitions of a single poly $(\mathrm{N}$ isopropylacrylamide) homopolymer chain in water," Macromolecules, vol. 31, no. 9, pp. 2972-2976, 1998.

[27] H. Chen, J. Li, Y. Ding, G. Zhang, Q. Zhang, and C. Wu, "Folding and unfolding of individual PNIPAM-g-PEO copolymer chains in dilute aqueous solutions," Macromolecules, vol. 38, no. 10, pp. 4403-4408, 2005. 

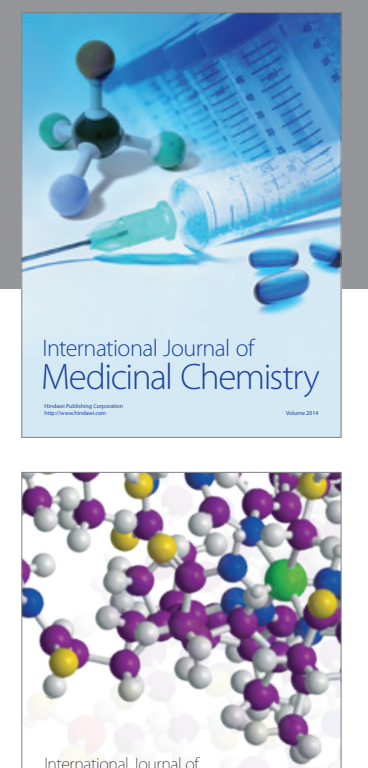

\section{Carbohydrate} Chemistry

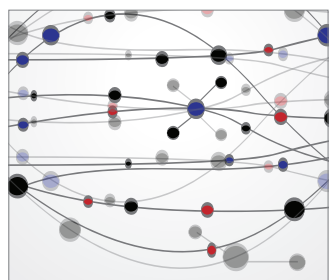

The Scientific World Journal
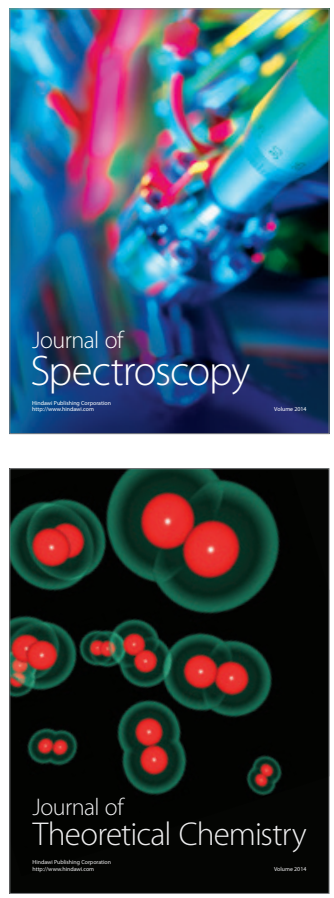
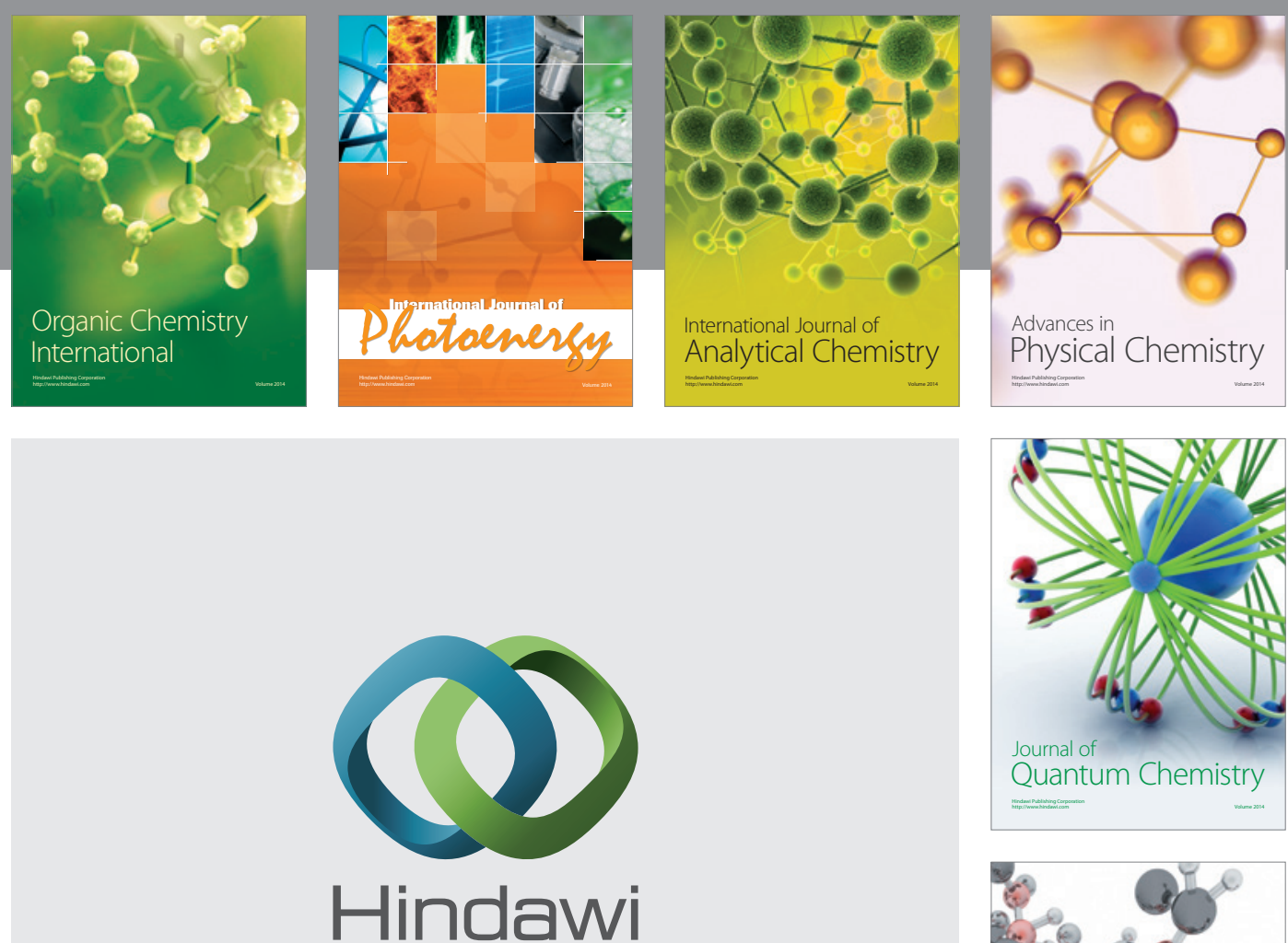

Submit your manuscripts at

http://www.hindawi.com

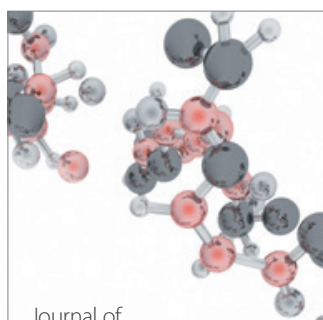

Analytical Methods

in Chemistry

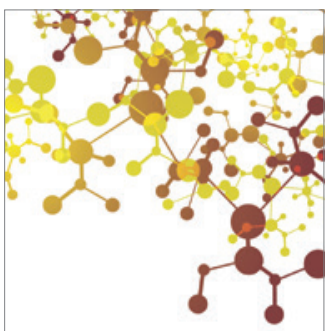

Journal of

Applied Chemistry

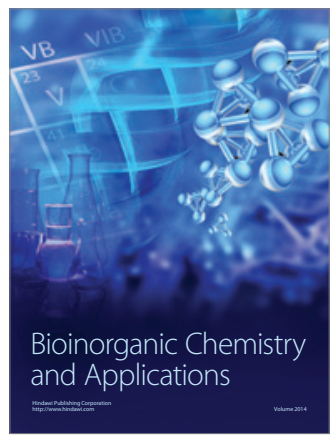

Inorganic Chemistry
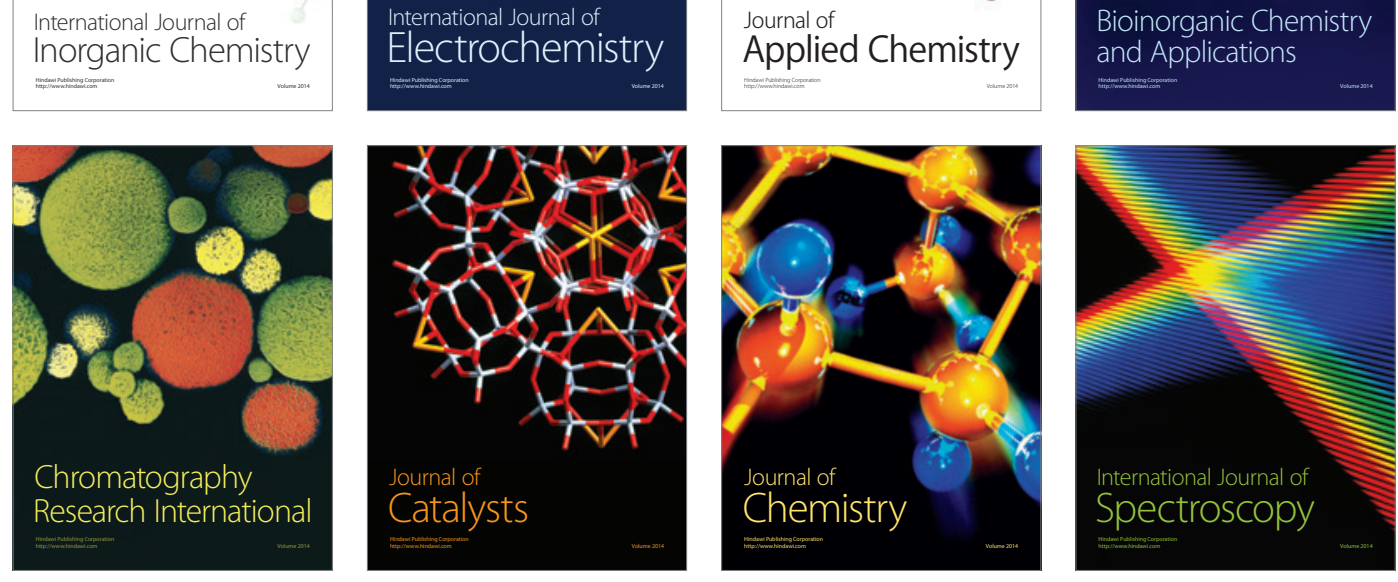